\title{
Multiplex transcriptional analysis of paraffin-embedded liver needle biopsy from patients with liver fibrosis
}

\author{
Nicholas R Staten ${ }^{1,5^{*}}$, Eric A Welsh', Kurex Sidik', Sandra A McDonald', Dawn R Dufield', Botoul Maqsodi², \\ Yunqing $\mathrm{Ma}^{2}$, Gary K McMaster ${ }^{2}$, Rodney W Mathews ${ }^{1}$, Robert H Arch ${ }^{3}$, Jaime L Masferrer ${ }^{1}$ \\ and Bernard E Souberbielle $e^{4,6^{*}}$
}

\begin{abstract}
Background: The possibility of extracting RNA and measuring RNA expression from paraffin sections can allow extensive investigations on stored paraffin samples obtained from diseased livers and could help with studies of the natural history of liver fibrosis and inflammation, and in particular, correlate basic mechanisms to clinical outcomes.

Results: To address this issue, a pilot study of multiplex gene expression using branched-chain DNA technology was conducted to directly measure mRNA expression in formalin-fixed paraffin-embedded needle biopsy samples of human liver. Twenty-five genes were selected for evaluation based on evidence obtained from human fibrotic liver, a rat BDL model and in vitro cultures of immortalized human hepatic stellate cells. The expression levels of these 25 genes were then correlated with liver fibrosis and inflammation activity scores. Statistical analysis revealed that three genes (COL3A1, KRT18, and TUBB) could separate fibrotic from non-fibrotic samples and that the expression of ten genes (ANXA2, TIMP1, CTGF, COL4A1, KRT18, COL1A1, COL3A1, ACTA2, TGFB1, LOXL2) were positively correlated with the level of liver inflammation activity.

Conclusion: This is the first report describing this multiplex technique for liver fibrosis and has provided the proof of concept of the suitability of RNA extracted from paraffin sections for investigating the modulation of a panel of proinflammatory and profibrogenic genes. This pilot study suggests that this technique will allow extensive investigations on paraffin samples from diseased livers and possibly from any other tissue. Using identical or other genes, this multiplex expression technique could be applied to samples obtained from extensive patient cohorts with stored paraffin samples in order to correlate gene expression with valuable clinically relevant information. This method could be used to provide a better understanding of the mechanisms of liver fibrosis and inflammation, its progression, and help development of new therapeutic approaches for this indication.
\end{abstract}

Keywords: Liver fibrosis, Liver inflammation, Multiplex gene expression

\section{Background}

Conducting gene expression analysis at the level of the organ of interest and correlating specific expression patterns to physiopathology, prognosis or early response to therapy remains a topic under intense investigation in liver fibrosis [1]. The ability to analyze gene expression

\footnotetext{
* Correspondence: nick@ky-pha.com; bernard.x.souberbielle@gsk.com 'Pfizer Global Research \& Development, 700 Chesterfield Parkway West, Chesterfield, MO 63017, USA

${ }^{5}$ Present address: Kypha, Inc., 4320 Forest Park Avenue, St Louis, MO 63108, USA

Full list of author information is available at the end of the article
}

from formalin-fixed paraffin-embedded (FFPE) tissue would be logistically useful because of access to banked samples which are usually paraffin-embedded specimens. For example, the description of this approach for hepatocellular carcinoma on paraffin-fixed tissue [2] has underscored the importance of the technology.

Here, we describe a multiplex gene expression pilot study using the bDNA technology QuantiGene ${ }^{\mathrm{TM}}$ Reagent System (Affymetrix, Santa Clara, CA, USA) for quantifying mRNA expression in FFPE liver samples [3]. Using this single multiplex assay, the expression levels of 25 genes were

\section{Biomed Central}

(c) 2012 Staten et al.; licensee BioMed Central Ltd. This is an Open Access article distributed under the terms of the Creative Commons Attribution License (http://creativecommons.org/licenses/by/2.0), which permits unrestricted use, distribution, and reproduction in any medium, provided the original work is properly cited. 
correlated with the extent of disease activity in fibrogenic chronic liver disorders. Included in the panel were genes known to be associated with liver fibrosis and hepatic stellate cell (HSC) activation, which have both been shown to correlate with inflammation [4]. In addition, several putative HSC housekeeping genes were chosen to assess for a correlation of HSC activity to stage of fibrosis or inflammation. Proof of concept was established showing that RNA extracted from paraffin sections could be used to investigate the modulation of a panel of proinflammatory and profibrogenic genes with this multiplex assay.

\section{Results}

\section{Identification of gene expression panel}

Previously performed bioinformatics analyses of whole genome microarray expression data identified 25 genes associated with fibrosis, HSC activation, or HSC housekeeping (Table 1). These expression data consisted of: 1) human fibrotic liver, 2) rat liver from a bile duct ligation fibrosis model, and 3) two separate human HSC activation models (LI90 and LX-2). The microarray data [5] are available from the ArrayExpress data repository (http://www. ebi.ac.uk/arrayexpress): human fibrotic liver (E-MEXP2589), rat fibrosis BDL model day-7 (E-MEXP-2583), plastic-activated LI90 cells (Accession No. E-MEXP-2582), and plastic-activated LX-2 cells (E-MEXP-2584). Microarray data were analyzed through the use of IPA (Ingenuity ${ }^{\circledR}$ Systems, www.ingenuity.com). Genes were selected based on their upregulation or downregulation in fibrotic human and/or rat samples versus matched non-fibrotic samples as well as their upregulation in plastic activated LI90 and LX-2 HSC lines [6]. Putative HSC housekeeping genes were chosen if they: 1) were highly expressed in HSCs, 2) did not change significantly with HSC activation, and 3) had been described as specifically expressed in HSCs or poorly expressed in other hepatic cell types. Ultimately, we identified 19 targets associated with fibrosis and/or HSC activation and seven HSC housekeeping genes that appeared to be highly and specifically expressed in resting or activated HSCs. One gene, TUBB, was identified as both a marker of fibrosis from a rat fibrosis BDL model and as an HSC housekeeping gene from LI90 and LX-2 activated HSC models, thus, bringing the number of genes to 25. An additional five nonspecific assay housekeeping genes (ACTB, TBP, RPL13A, PPIA, and UBC) were recommended by the manufacturer of the QuantiGene ${ }^{\mathrm{TM}}$ Multiplex bDNA assay (Affymetrix, Santa Clara, CA, USA) to normalize expression of the 25-gene panel and therefore create a 30-plex gene expression array.

\section{HSC, hepatic stellate cells}

Performance of the multiplex assay with FFPE liver samples The technique was first standardized on cadaver liver tissue blocks. Five sections $\left(60 \mathrm{~mm}^{2}\right)$ of $8-\mu \mathrm{m}$ thick sections from cadaver liver tissue blocks resulted in the most reproducible results. The 30-plex assay was then used to assess gene expression in all 25 needle biopsies. The optimum quantity of liver tissue for best sensitivity and reproducibility was equivalent to two to three needle biopsy sections (approximately 20 to $30 \mathrm{~mm}^{2}$ ) $8-\mu \mathrm{m}$ thick for detection of all 30 genes tested. QuantiGene ${ }^{\text {тм }}$ 2.0 multiplex intraassay coefficient of variations $(\mathrm{CVs})$ were less than $10 \%$ for duplicate sections and less than $15 \%$ for triplicate sections. The interassay CVs were less than $20 \%$ for technical replicates. Data for four genes from the original set of 25 were discarded due to weak signal intensities across the majority of samples (CXCL2 and $S Y P$ ) or in more than $50 \%$ of samples (ARNT2 and $C P E B 1)$. In addition, one of the QuantiGene ${ }^{\mathrm{TM}}$ assay normalization genes, $U B C$, was not included for further analysis due to inconsistent behavior across multiple strip testing.

Six genes were identified with significantly upregulated expression in fibrotic liver: $L O X L 2, T U B B, C O L 1 A 1, T B P$ (all $P<0.0001), C O L 3 A 1$ ( $P=0.0002)$, and $P 311$ ( $P=$ $0.0008)$. One gene showed significantly downregulated expression in fibrotic liver: KRT18 $(P=0.0002)$. Among these seven differentially expressed genes, TBP was originally selected as a gene for assay normalization.

\section{Development of a logistic model for assessing liver fibrosis progression}

A logistic model was also established to determine those informative genes that could provide insight into liver fibrosis progression [7]. The disease status as a binary response was modeled on the covariates, that is, the gene expression measurements. First, each gene was evaluated separately by fitting the simple logistic model. From this preliminary one-gene-at-a-time modeling step, nine out of 25 genes were selected, including the seven genes listed above along with two additional genes: $A C T B$ and PPIA. A logistical model was then built by utilizing the forward selection method based on the nine genes from the previous step using the SAS PROC LOGISTIC procedure [8]. Comparison of the modeling results with the $t$-test, principle component analysis (PCA), and partial least square (PLS) analyses resulted in the selection of three genes (COL3A1, KRT18, and TUBB, ) as potential informative covariates. However, this logistical model needs to be tested with additional data in order to validate this model and establish it as a useful prediction model for liver fibrosis status.

\section{Correlation between gene expression and disease activity}

Regardless of the number of components, no correlation with the stage of fibrosis $\left(Q^{2}\right.$, the cross-validated $\left.R^{2}\right)$ could be detected. However, the expression of 12 out of 21 genes (57\%) showed either strong positive (ANXA2, 
Table 1 A 30-plex gene expression panel, including five human gene normalization controls and the two human ribosomal (DNA and RNA) controls used in singleplex

\begin{tabular}{|c|c|c|c|}
\hline Gene & Gene name & $\begin{array}{l}\text { GenBank } \\
\text { accession }\end{array}$ & Rationale \\
\hline $\begin{array}{l}185 \text { ribosomal } \\
\text { DNA }\end{array}$ & . & NR_003286 & $\begin{array}{l}\text { Tissue Quality \& Quantity } \\
\text { Assessment }\end{array}$ \\
\hline $\begin{array}{l}\text { 28S ribosomal } \\
\text { RNA }\end{array}$ & . & NR_003287 & " " \\
\hline$A C T B$ & Actin, beta & NM_001101 & Normalization \\
\hline$\overline{P P I A}$ & Peptidylprolyl isomerase A (cyclophilin A) & NM_021130 & " " \\
\hline RPL13A & Ribosomal protein L13a & NM_012423 & " " \\
\hline$T B P$ & TATA box binding protein & NM_003194 & " " \\
\hline$\overline{U B C}$ & Ubiquitin C & NM_021009 & " " \\
\hline ACTA2 & Actin, alpha 2, smooth muscle, aorta & NM_001613 & $\begin{array}{l}\text { Fibrosis and/or HSC Activation } \\
\text { Marker }\end{array}$ \\
\hline ANXA2 & Annexin A2 & NM_001002857 & " " \\
\hline ARNT2 & Aryl-hydrocarbon receptor nuclear translocator 2 & NM_014862 & HSC Housekeeping \\
\hline COLIA1 & Collagen, type I, alpha 1 & NM_000088 & $\begin{array}{l}\text { Fibrosis and/or HSC Activation } \\
\text { Marker }\end{array}$ \\
\hline COL3A1 & Collagen, type III, alpha 1 & NM_000090 & " " \\
\hline COL4A1 & Collagen, type IV, alpha 1 & NM_001845 & " " \\
\hline CPEB1 & Cytoplasmic polyadenylation element binding protein 1 & NM_030594 & HSC Housekeeping \\
\hline CTGF & Connective tissue growth factor & NM_001901 & $\begin{array}{l}\text { Fibrosis and/or HSC Activation } \\
\text { Marker }\end{array}$ \\
\hline CTHRC1 & Collagen triple helix repeat containing 1 & NM_138455 & " " \\
\hline$\overline{C X C L 2}$ & $\begin{array}{l}\text { Chemokine (C-X-C motif) ligand } 2 \text {; CINC-2a, GROb, Gro2, MIP-2, MIP- } \\
2 \mathrm{a}\end{array}$ & NM_002089 & " " \\
\hline EDN1 & Endothelin 1 & NM_001955 & " " \\
\hline FOXF1 & Forkhead box F1 & NM_001451 & HSC Housekeeping \\
\hline HAMP & Hepcidin antimicrobial peptide & NM_021175 & $\begin{array}{l}\text { Fibrosis and/or HSC Activation } \\
\text { Marker }\end{array}$ \\
\hline HSPA1A & Heat shock $70 \mathrm{kDa}$ protein $1 \mathrm{~A}$ & NM_005345 & " " \\
\hline IGFBP6 & Insulin-like growth factor binding protein 6 & NM_002178 & HSC Housekeeping \\
\hline KRT18 & Keratin 18 ; cytokeratin 18 , cell proliferation inducing protein 46 & NM_000224 & $\begin{array}{l}\text { Fibrosis and/or HSC Activation } \\
\text { Marker }\end{array}$ \\
\hline LOXL2 & Lysyl oxidase-like 2 & NM_002318 & " " \\
\hline MRGPRF & MAS-related GPR, member F & NM_145015 & HSC Housekeeping \\
\hline$P 311$ & Neuronal protein 3.1, C5orf13 & NM_004772 & " " \\
\hline SYP & Synaptophysin & NM_003179 & $\begin{array}{l}\text { Fibrosis and/or HSC Activation } \\
\text { Marker }\end{array}$ \\
\hline TGFB1 & Transforming growth factor, beta 1 & NM_000660 & " " \\
\hline TGFB2 & Transforming growth factor, beta 2 & NM_003238 & " " \\
\hline TIMP1 & TIMP metallopeptidase inhibitor 1 & NM_003254 & " " \\
\hline TNF & Tumor necrosis factor (TNF superfamily, member 2) & NM_000594 & " " \\
\hline$\overline{T U B B}$ & Tubulin, beta & NM_178014 & HSC Housekeeping \& Fibrosis Marker \\
\hline
\end{tabular}

TIMP1, CTGF, COL4A1, KRT18, COL1A1, COL3A1, ACTA2, TGFB1, LOXL2) or negative (TUBB, P311) correlation with necroinflammation score (Figure 1). These 12 genes were selected as yielding the most discriminant PCA and PLS models. The two negatively correlated genes chosen as HSC housekeeping genes, TUBB and P311, did not perform as well as the other 10 genes in the PLS analysis, but contributed to the separation of controls from disease samples in the PCA analysis. The two-component PCA captured $76 \%$ of the variance, with a cross-validated (leave $1 / 7^{\text {th }}$ out) $\mathrm{Q}^{2}$ of 0.63 (data not shown). Given the correlation with disease activity observed within diseased samples, a single-component PLS model was built within the diseased samples using 


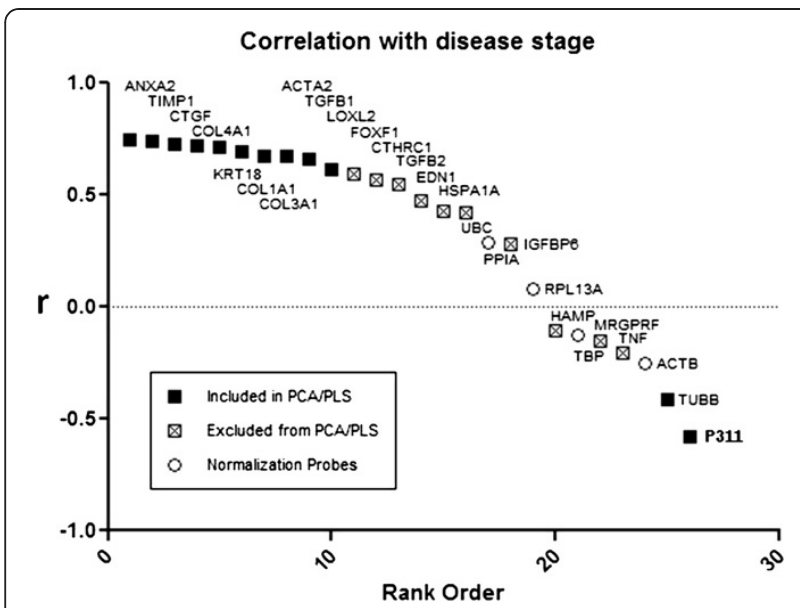

Figure 1 Correlation with necroinflammation activity scoring.

The Pearson correlation ( $r$ ) of the log10 (gene expression) vector with inflammation activity score is plotted versus the correlation rank order (computed correlation coefficient between the ranks of gene expression and inflammation activity) for each probe. The ten most highly correlated (positive) genes ( $\mathbf{\square}$ ) were selected for inclusion in the principle component analysis (PCA)/ partial least squares (PLS) models, as well as two anticorrelated (negative) genes (TUBB, P311) (घ).

the selected 12 probes. The resulting model was able to predict the activity grading of tissue samples of fibrogenic chronic liver diseases with a $\mathrm{R}^{2}$ of 0.69 and $\mathrm{Q}^{2}$ of 0.66 with a maximum error of approximately \pm 0.5 stage (Figure 2). Inclusion of a second component in the PLS model was not statistically justified.

\section{Discussion}

This report describes a pilot study evaluating a multiplex gene analysis assay, relevant for complex diseases with limited tissue availability, which proved reliable for the study of tissue samples of fibrogenic chronic liver diseases using FFPE needle biopsy samples. The optimum quantity of liver tissue for best sensitivity and reproducibility was equivalent to two to three needle biopsy sections 8- $\mu \mathrm{m}$ thick for detection of all genes tested. Using this approach, the expression of ten genes, known to be associated with liver fibrosis and/or HSCs activation, were identified as positively correlating with necroinflammatory activity, whereas two HSC housekeeping genes were identified as negatively correlating with activity, though we could not find a strong correlation between gene expression and fibrosis stage.

We used the bDNA technology QuantiGene ${ }^{\mathrm{TM}}$ Reagent System for quantifying mRNA expression. The technical advantage of the sandwich nucleic acid hybridization assay [3] lies in amplification of reporter signals without enzymatic amplification of the target mRNA, which allows direct measurement of mRNA in tissue homogenates, overcoming issues associated with mRNA

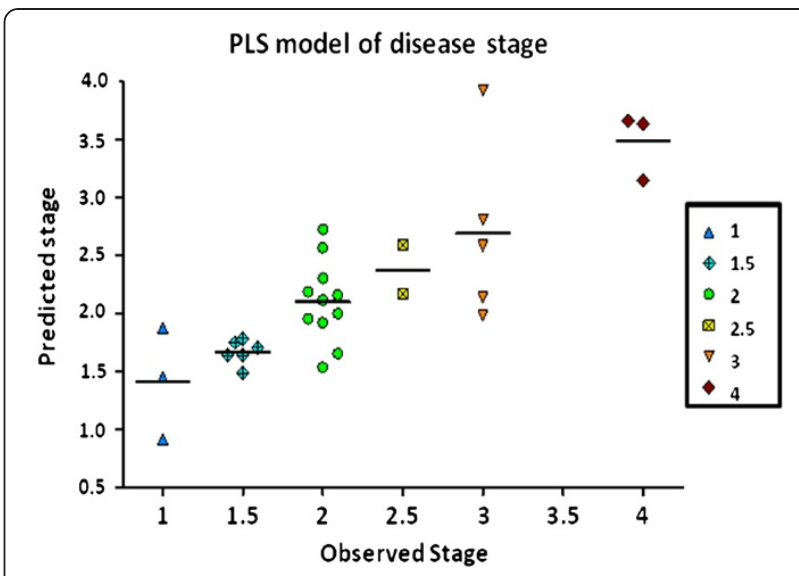

Figure 2 Partial least squares model of necroinflammation activity grading. A one-component partial least squares (PLS) model was trained on the twelve selected genes (ten positive and two negative correlated) versus observed necroinflammation activity stage within the diseased needle biopsy samples alone $\left(R^{2}: 0.69, Q^{2}\right.$ : 0.66). Necroinflammation stage is predicted to within approximately \pm 0.5 stage.

extraction. This technology was chosen over a qPCRbased assay method for two primary reasons: 1) QuantiGene $^{\mathrm{TM}}$ detection can accurately measure mRNA in FFPE samples whereas qPCR cannot reliably measure mRNA, which has an average size of 100 bases; and 2) QuantiGene $^{\mathrm{TM}}$ can be multiplexed more easily than qPCR which is more suited for expression analysis of mRNA extracted from fresh or frozen samples. Prior attempts to employ qPCR on a subset of selected genes in paraffin resulted in no detectable gene expression in paraffin liver RNA and resulted in no detectable gene expression or gene expression beyond the limit of detection (Staten, data not published). Thus, we were not able to use qPCR to compare gene expression between samples or correlate between qPCR and bDNA technologies.

The selection of the genes to be evaluated was made arbitrarily on the basis of a mixed combination of data obtained from human fibrotic liver, a rat BDL model and in vitro culture of immortalized hepatic stellate cells, namely L190 and LX2, and therefore the selected genes are likely related to established inflammation and fibrosis. Other genes could be used in this multiplex assay to address complementary, but different, questions. For example we did not select all of the candidate genes strictly on the basis of a subtraction analysis done by comparing gene expression in fibrotic liver (or activated HSC) and normal liver (or quiescent stellate cells), as described by others previously $[9,10]$. This alternative approach may be more appropriate to study the difference of gene expression between disease state and normal liver. However, our approach and the choice of genes used in the present study are more appropriate for investigating the modulation of inflammation and 
fibrosis between different samples of diseased liver, and could also be applied to verify the modulation of these genes following a period of treatment (for example, predictor of antifibrotic and anti-inflammatory response).

Prognostic factors of rapid progression of liver fibrosis to cirrhosis based on liver biopsy, but also on somatic genetic markers, have been described [11,12]. For example, Asselah and colleagues [13] identified 11 genes that differentiate mild from moderate fibrosis based on their respective expression levels. But only two of these genes (COL1A1, TIMP1) overlapped with our study. For identification of potential therapeutic targets, this multiplex assay can be customized with other genes of interest. Liver fibrosis is a disease characterized by collagen deposition [14] and we included in the multiplex assay multiple genes coding for proteins involved in extra cellular matrix formation, deposition and turnover (COL1A1, COL3A1, COL4A1, ACTA2 and TIMP1); and one gene encoding a component of the cytoskeleton (KRT18). However, in our report, the highest correlation with inflammatory activity stage was observed for annexin 2 (ANXA2). ANXA2 has many described functions but its role in the hepato-biliary system is not fully understood. It is expressed in many cells including hepatocytes, HSCs [15] and cholangiocytes [16]. ANXA2 is involved in the plasminogen/plasmin system with fibrinolytic effects promoting clot dissolution in alcoholic liver cirrhosis [15]. In inflammatory cholangiopathy ANXA2 can mediate a compensatory effect for the impaired bicarbonate secretion of cholangiocytes through modulation of anion exchanger [16]. ANXA2 has been shown to be expressed as a vitamin D binding protein on hepatocytes and HSCs. Some of these interactions could be important for liver fibrogenesis and inflammation through a TGF $\beta$ independent mechanism [17].

\section{Conclusions}

In conclusion, the results of this pilot study provide feasibility evidence (proof of concept) for the use of multiplex gene expression methods on FFPE samples from chronic fibrotic liver tissues. However, because of possible limitations of our study (choice of genes, limited samples used for analysis, scoring and grading done only with METAVIR), these results are not yet conclusive for the definition of the diagnostic potential of the panel of genes employed. Indeed, we were unable to source FFPE fine needle biopsies from nonfibrotic control livers. Furthermore, our analysis includes two distinct tissue sources, that is, cadaveric samples (fibrotic and nonfibrotic livers) and needle biopsies from fibrotic livers. Thus, the time to process samples from cadavers between time of death and time of processing ( 4 to 10 hours post mortem) may impact the mRNA levels of specific hepatic genes. Therefore, our results should be corroborated by further studies including an adequate number of cases thoroughly characterized in terms of etiology, grading and staging, and with adequate sampling conditions. Following this demonstration, the same technical multiplex scheme could be applied to samples obtained from extensive cohorts with stored paraffin samples to obtain more precise and clinically relevant information. In particular, it will be possible to correlate gene expression (employing a customized multiplex gene panel), with histopathology (stage and activity), clinical and biochemical data, and prognostic indexes (time to cirrhosis, liver related events, survival, etcetera) in retrospective or prospective analysis.

\section{Methods}

\section{Fixed human liver samples}

Human FFPE block samples were acquired from various external academic sources in compliance with Pfizer's human tissue policy and approval by the Institutional Review Board of the source institution. Samples were deidentified and patient identities were not traceable by Pfizer at any point in time. Needle biopsies from fibrotic livers were collected from $18 \mathrm{HCV}$ and seven nonalcoholic steatohepatitis (NASH) patients (14 male and 11 females; 23 to 65 years of age). To the best of our knowledge, these biopsies were fixed within 0.5 hours of procurement and processed through surgical pathology at the home institutions. In addition, we obtained 11 nonfibrotic and five (HCV-negative) fibrotic liver samples collected from cadavers fixed with a lag-time of 4 to 10 hours postmortem. These FFPE blocks were sectioned ( $8 \mu \mathrm{m}$ thick), stained with hematoxylin and eosin, and transferred into $1.5 \mathrm{~mL}$ microcentrifuge tubes for further processing [18].

\section{Fibrosis and activity scoring}

All of the hematoxylin and eosin-stained liver samples were assessed by a single pathologist at Pfizer for inflammatory activity and changes in tissue architecture using scoring systems adapted from the Knodell system for inflammation [19] and the METAVIR scoring system for fibrosis [20]. Inflammation grading was indicated as: $0=$ no inflammation, $1=$ minimal inflammation, $2=$ mild inflammation, $3=$ moderate inflammation, and $4=$ marked/severe inflammation, with half point scores used at the pathologist's discretion. The presence of necrotic hepatocytes was accounted for in the overall grading scheme. Fibrosis grading was indicated as: $0=$ normal architecture, 1 = minimally expanded portal tracts, $2=$ periportal fibrosis, 3 = bridging fibrosis, and $4=$ cirrhosis.

QuantiGene $^{\mathrm{TM}}$ multiplex bDNA assay for the 30-plex gene expression panel

FFPE tissue homogenates were prepared as previously described [21]. Briefly, FFPE sections were homogenized in tissue homogenizing solution (THS) (Affymetrix Inc. Santa Clara, CA) supplemented with $500 \mu \mathrm{g} / \mathrm{mL}$ 
Proteinase $\mathrm{K}$ and incubated for 6 hours at $65^{\circ} \mathrm{C}$. The tissue homogenate was processed immediately or stored at $-80^{\circ} \mathrm{C}$ until use.

For the cadaver liver tissue blocks, five sections of 60 $\mathrm{mm}^{2}$ (each $8 \mu \mathrm{m}$ thick) resulted in the most reproducible results (data not shown). These sections were homogenized individually in $300 \mu \mathrm{L}$ of THS and digested with $500 \mu \mathrm{g} / \mathrm{mL}$ Proteinase $\mathrm{K}$ for 6 hours at $65^{\circ} \mathrm{C}$. For needle biopsy samples, two sections from each of the liver needle biopsies ranging from approximated 20 to $30 \mathrm{~mm}^{2}$ ( $8 \mu \mathrm{m}$ thick) were homogenized in $150 \mu \mathrm{L}$ THS using 500 $\mu \mathrm{g} / \mathrm{mL}$ proteinase $\mathrm{K}$ for 6 hours at $65^{\circ} \mathrm{C}$. The mRNA quality and quantity were assessed using the $18 \mathrm{~S}$ rRNA probe set $(1 \mu \mathrm{L}$ homogenate) and $28 \mathrm{~S}$ rRNA probe set $(0.001 \mu \mathrm{L}$ homogenate) in duplicate on all homogenates [21]. Finally, $40 \mu \mathrm{L}$ of homogenate of each sample were tested in triplicate using the 30-plex gene panel.

The multiplex bDNA assays were run as recommended in the QuantiGene ${ }^{\mathrm{TM}}$ Plex 2.0 Reagent System User Manual. Probe design software [22] was used to generate probe sets for singleplex or multiplex bDNA assays [3]. Probe sets were designed and synthesized by Affymetrix, Inc. (Santa Clara, CA, USA). Samples containing $40 \mu \mathrm{L}$ of homogenate were mixed with pooled multiplex probe sets and capture beads (2,000 beads per gene per assay) prior to hybridization in $100 \mu \mathrm{L}$ total volume, for 20 hours at $55^{\circ} \mathrm{C}$. Hybridization reactions were transferred to a 0.45 $\mu \mathrm{m}$ filter plate (Millipore, Billerica, MA, USA), followed by sequential hybridization at $55^{\circ} \mathrm{C}$ with the bDNA amplifier and $5^{\prime}$-dT(biotin)-conjugated label probe. Unbound materials were washed from beads complexed with probe set and mRNA by alternating filtration and the addition of wash buffer (0.1X SSC, $0.03 \%$ lithium lauryl sulfate). Two washes were performed after each step. After the final wash, streptavidin-conjugated R-phycoerythrin (SAPE) was added and incubated at room temperature for 30 minutes. Analysis was performed after an additional wash to remove unbound SAPE.

\section{Data analysis}

Background signals (relative light units) were determined in the absence of RNA and subtracted from signals obtained with RNA, setting any negative signals to zero. Background subtracted signals were used to calculate the coefficient of variation $(\mathrm{CV})$ and sensitivity of all assays, as well as for normalization of the RNA expression of each gene. Sensitivity was evaluated by determining the limit of detection, defined as target RNA concentration at which the signal is three standard deviations above background. Data were normalized by four assay housekeeping genes (TBP, ACTB, PPIA, and RPL13A) using the geometric mean [23] for each sample. The $U B C$ assay housekeeping gene was omitted due to inconsistent behavior across multiple strip assays.

\section{Statistical analysis}

In order to identify significantly differentially expressed liver fibrotic genes, a screening approach was first followed to compare fibrotic (sourced from needle biopsy and cadavers) and nonfibrotic liver tissue (sourced only from cadavers) using the two-sample $t$-test on the gene expression data of 26 genes (excluding four genes of the 30 genes for analysis: SYP, CXCL2, ARNT2, and CBEP1). Considering multiplicity testing issues, comparisons were controlled using the false discovery rate at the 5\% test level [24]. In order to correlate liver fibrosis and inflammation stages with gene expression profiles, principle component analysis (PCA) and partial leastsquares analysis (PLS) (Evince software package, Umbio, Umeå, Sweden) were performed on log transformed intensities, scaled and centered to unit variance.

\section{Abbreviations}

CV: coefficient of variation; ECM: extra cellular matrix; FFPE: formalin-fixed paraffin-embedded; HCV: hepatitis C virus; HSC: hepatic stellate cells; NASH: non-alcoholic steatohepatitis; H\&E: hematoxylin and eosin; PCA: principle component analysis; PLS: partial least square; qPCR: quantitative PCR; RNA: ribonucleic acid; THS: tissue homogenizing solution; SAPE: streptavidin-conjugated R-phycoerythrin; THS: tissue homogenizing solution.

\section{Competing interest}

BM, YM and GKM are employees of Affymetrix, which has developed the multiplex technique described in this paper.

\section{Authors' contributions}

$N S, E W, K S, S M, D D, B M, G M, R M, M J$ contributed to the design, acquisition of data, analysis and interpretation and to the draft of the manuscript. NS, RA and BS contributed also to the analysis and interpretation of the data, and directed and drafted the manuscript. All authors read and approved the final manuscript.

\section{Authors' information}

RA's current address: GlaxoSmithKline (China) R\&D Co., Ltd. Building 3, 898 Halei Road. Zhangjiang Hi-Tech Park, Pudony. Shangai 201203, China. DD's current address: Pfizer Global Research \& Development, 1 Burtt Rd, Andover, MA 01810, USA.

\section{Acknowledgements}

We would like to thank Professor Massimo Pinzani for his critical review of our manuscript.

\section{Financial support}

This study was supported by Pfizer.

\section{Author details}

${ }^{1}$ Pfizer Global Research \& Development, 700 Chesterfield Parkway West, Chesterfield, MO 63017, USA. ${ }^{2}$ Affymetrix, 3380 Central Expressway, Santa Clara, CA 95051, USA. ${ }^{3}$ Pfizer Worldwide Research \& Development, Asia Research 575 Maryville Centre Drive, Saint Louis, MO 63141, USA. ${ }^{4}$ Pfizer Clinical Research, Ramsgate Road, Sandwich, Kent CT139NJ, UK. ${ }^{5}$ Present address: Kypha, Inc., 4320 Forest Park Avenue, St Louis, MO 63108, USA. ${ }^{6}$ Present address: GSK, Experimental Medicine Unit, Gunnels Wood Road, Stevenage, Herst SG1 2NY, UK.

Received: 18 October 2012 Accepted: 11 December 2012 Published: 27 December 2012

\section{References}

1. Hannivoort RA, Hernandez-gea V, Friedman SL: Genomics and proteomics in liver fibrosis and cirrhosis. Fibrogenesis \& Tissue Repair 2012, 5:1. 
2. Hoshida Y, Villanueva A, Kobayashi M, Peix J, Chiang DY, Camargo A, Gupta S, Moore J, Wrobel MJ, Lerner J, Reich M, Chan JA, Glickman JN, Ikeda K, Hashimoto M, Watanabe G, Daidone MG, Roayaie S, Schwartz M, Thung S, Salvesen HB, Gabriel S, Mazzaferro V, Bruix J, Friedman SL, Kumada H, Llovet JM, Golub TR: Gene expression in fixed tissues and outcome in hepatocellular carcinoma. N Engl J Med 2008, 359:1995-2004.

3. Flagella M, Bui S, Zheng Z, Nguyen CT, Zhang A, Pastor L, Ma Y, Yang W, Crawford KL, McMaster GK, Witney F, Luo Y: A multiplex branched DNA assay for parallel quantitative gene expression profiling. Anal Biochem 2006, 352:50-60.

4. Cheng K, Mahato Rl: Gene modulation for treating liver fibrosis. Crit Rev Ther Drug Carrier Syst 2007, 24:93-146.

5. Shimada H, Staten NR, Rajagopalan LE: TGF- $\beta 1$ mediated activation of Rho kinase induces TGF- $\beta 2$ and endothelin- 1 expression in human hepatic stellate cells. J Hepatol 2011, 54:521-528.

6. Xu L, Hui AY, Albanis E, Arthur MJ, O'Byrne SM, Blaner WS, Mukherjee P, Friedman SL, Eng FJ: Human hepatic stellate cell lines, LX-1 and LX-2: new tools for analysis of hepatic fibrosis. Gut 2005, 54:142-151.

7. Agresti A: Categorical Data Analysis. 2nd edition. Hoboken, NJ, USA: Wiley; 2002

8. SAS Institute, Inc: The GENMOD Procedure. Cary, NC: SAS Institute, Inc; 1999.

9. Boers W, Aarrass S, Linthorst C, Pinzani M, Elferink RO, Bosma P: Transcriptional profiling reveals novel markers of liver fibrogenesis: gremlin and insulin-like growth factor binding proteins. J Biol Chem 2006, 281:16289-16295.

10. De Minicis S, Seki E, Uchinami H, Klume J, Zhang Y, Brenner DA, Schwabe RF: Gene expression profiles during hepatic stellate cell activation in culture and in vivo. Gastroenterology 2007, 132:1937-1946.

11. Missiha SB, Ostrowski M, Heathcote EJ: Disease progression in chronic hepatitis C: modifiable and non-modifiable factors. Gastroenterology 2008, 134:1699-1714.

12. Trépo E, Potthoff A, Pradat $P$, Bakshi R, Young B, Lagier R, Moreno C, Verset L, Cross R, Degré D, Lemmers A, Gustot T, Berthillon P, Rosenberg W, Trépo C, Sninsky J, Adler M, Wedemeyer $\mathrm{H}$ : Role of cirrhosis risk score for the early prediction of fibrosis progression in hepatitis $C$ patients with minimal liver disease. J Hepatol 2011, 55:38-44.

13. Asselah T, Bieche I, Laurendeau I, Paradis V, Vidaud D, Degott C, Martinot M, Bedossa $P$, Valla D, Vidaud M, Marcellin P: Liver gene expression signature of mild fibrosis in patients with chronic hepatitis C. Gastroenterology 2005, 129:2064-2075.

14. Chen CZC, Raghunath M: Focus on collagen: in vitro systems to study fibrogenesis and antifibrosis - state of the art. Fibrogenesis \& Tissue Repair 2009, 2:7. doi:10.1186/1755-1536-2-7.

15. Seth D, Hogg PJ, Gorrell MD, McCaughan GW, Haber PS: Direct effects of alcohol on hepatic fibrinolytic balance: implications for alcoholic liver disease. J Hepatol 2008, 48:614-627.

16. Kido O, Fukushima K, Ueno Y, Inoue J, Jefferson DM, Shimosegawa T: Compensatory role of inducible annexin A2 for impaired biliary epithelial anion-exchange activity of imflammatory cholangiopathy. Lab Invest 2009, 89:1374-1386.

17. Gressner OA, Lahme B, Gressner AM: Gc-globulin (vitamin D binding protein) is synthesized and secreted by hepatocytes and internalized by hepatic stellate cells through $\mathrm{Ca} 2+-$ dependent interaction with the megalin/gp330 receptor. Clin Chim Acta 2008, 390:28-37.

18. Yang W, Maqsodi B, Ma Y, Bui S, Crawford KL, McMaster GK, Witney F, Luo Y: Direct quantification of gene expression in homogenates of formalin-fixed, paraffin-embedded tissues. Biotechniques 2006, 40:481-486.

19. Knodell RG, Ishak KG, Black WC, Chen TS, Craig R, Kaplowitz N, Kiernan TW, Wollman J: Formulation and application of a numerical scoring system for assessing histological activity in asymptomatic chronic active hepatitis. Hepatology 1981, 1:431-435.

20. Poynard T, Bedossa P, Opolon P: Natural history of liver fibrosis progression in patients withchronic hepatitis C. The OBSVIRC, METAVIR, CLINIVIR, and DOSVIRC groups. Lancet 1997, 349:825-832.

21. Knudsen BS, Allen AN, McLerran DF, Vessella RL, Karademos J, Davies JE, Maqsodi B, McMaster GK, Kristal AR: Evaluation of the branched-chain DNA assay for measurement of RNA in formalin-fixed tissues. J Mol Diagn 2008, 10:169-176.

22. Bushnell S, Budde J, Catino T, Cole J, Derti A, Kelso R, Collins ML, Molino G, Sheridan P, Monahan J, Urdea M: ProbeDesigner: for the design of probesets for branched DNA (bDNA) signal amplification assays. Bioinformatics 1999, 15:348-355.

23. Vandesompele J, De Preter K, Pattyn F, Poppe B, Van Roy N, De Paepe A Speleman F: Accurate normalization of real-time quantitative RT-PCR data by geometric averaging of multiple internal control genes. Genome Biol 2002, 3:RESEARCH0034.

24. Benjamini $Y$, Hochberg Y: Controlling the false discovery rate: a practical and powerful approach to multiple testing. J Royal Stat Soc 1995, 57:289-300.

doi:10.1186/1755-1536-5-21

Cite this article as: Staten et al:: Multiplex transcriptional analysis of paraffin-embedded liver needle biopsy from patients with liver fibrosis. Fibrogenesis \& Tissue Repair 2012 5:21.

\section{Submit your next manuscript to BioMed Central and take full advantage of:}

- Convenient online submission

- Thorough peer review

- No space constraints or color figure charges

- Immediate publication on acceptance

- Inclusion in PubMed, CAS, Scopus and Google Scholar

- Research which is freely available for redistribution 